\title{
Tracking of lung function parameters and the longitudinal relationship with lifestyle
}

\author{
J.W.R. Twisk*, B.J. Staal*, M.N. Brinkman*, H.C.G. Kemper*, W. van Mechelen*,
}

Tracking of lung function parameters and the longitudinal relationship with lifestyle. J.W.R. Twisk, B.J. Staal, M.N. Brinkman, H.C.G. Kemper, W. van Mechelen. OERS Journals Ltd 1998.

ABSTRACT: The purpose of this study was to analyse tracking (i.e. relative stability over time/predictability of future values by early measurements) of lung function parameters and their longitudinal relationship with lifestyle (smoking, alcohol consumption, daily physical activity, neuromotor and cardiopulmonary fitness, and dietary intake of retinol and polyunsaturated fatty acids (PUFA)).

Data were obtained from the observational Amsterdam Growth and Health Study, a longitudinal study with six repeated measurements between ages 13-27 yrs $(n=167)$. The statistical analyses were carried out with generalized estimating equations.

The following "stability" coefficients were found: for forced vital capacity (FVC) in males 0.66 (95\% confidence interval (CI): 0.54-0.77) and in females 0.51 (95\% CI: 0.43-0.60); for forced expiratory volume in one second (FEV1) in males 0.65 (95\% CI: $0.50-0.80)$, in females $0.53(95 \%$ CI 0.46-0.60); for peak expiratory flow (PEF) in both males and females 0.41 (95\% CI: 0.31-0.51). Positive relationships were found between alcohol consumption and FVC and FEV1 and between neuromotor fitness and PEF and (only for males) with FVC and FEV1. Physical activity was inversely related to PEF and the intake of PUFA positively related to FVC and FEV1. Smoking was related to a decrease in FVC and FEV1; changes in physical activity positively correlated to changes in FVC.

In conclusion, high to moderate stability/tracking was observed for forced vital capacity and forced expiratory volume in one second; for peak expiratory flow it was slightly lower. Preventive strategies regarding improvements of lung function should focus on smoking cessation and improving daily physical activity.

Eur Respir J 1998; 12: 627-634.
*Institute for Research in Extramural Medicine and $\$$ Dept of Social Medicine, Vrije Universiteit, Amsterdam, The Netherlands

Correspondence: J.W.R. Twisk

EMGO Institute, Vrije Universiteit

Van der Boechorststraat 7

1081 BT Amsterdam

The Netherlands

Fax: 31204448181

Keywords: Epidemiologic methods lifestyle

longitudinal studies

respiratory function tests

Received: September 21997

Accepted after revision May 51998

This study was supported by grants from by the Dutch Heart Foundation, the Dutch Prevention Fund, the Dutch Ministry of Well Being and Public Health, the Diary Foundation on Nutrition and Health and the Netherlands Olympic Committee/Netherlands Sports Federation (NOC* NSF).
In the last decades lung function parameters have often been used as health indicators in epidemiological and clinical research [1-3]. Many of these studies however, are cross-sectionally designed and therefore not suitable to describe the development of lung function parameters over time. An important aspect in describing the longitudinal development of a certain health indicator over time is called tracking. It not only depends upon the relative stability of a parameter in time, but it also gives an indication of the predictability of future values by early measurements [4]. Therefore, tracking deals with the detection of subjects "at risk". If tracking exists for a certain health indicator, subjects "at risk" can be identified at an early age, and therefore preventive strategies can start as soon as possible. In the epidemiological literature tracking analysis is mostly described for health indicators regarding coronary heart disease, like lipoprotein levels and blood pressure [5], but not for lung function parameters, although "impaired" lung function without clinical symptoms can be seen as a predictor (risk factor) for the development of lung disease. Thus, the analysis of tracking of lung function parameters in subjects without the presence of clinical symptoms can provide important information whether or not it is worthwhile to screen subjects at an early age, in order to start preventive strategies. This is an important issue because chronic lung disease is an important cause of death, and has not shown a decline in mortality over the past 20 yrs, in contrast to other major chronic diseases. Furthermore, for diseases like coronary heart disease and cancer, large public health efforts have been mounted for detection, risk factor intervention, and prevention, but no such programmes have been implemented for chronic lung disease [6].

In order to develop preventive strategies for lung disease, it is important to investigate which parameters influence the development of lung function. There is some evidence that the evolution of lung function parameters is related to specific lifestyle parameters such as smoking behaviour, habitual physical activity, physical fitness, dietary intake, and alcohol consumption. Smoking is reported to have a deleterious effect on lung function [7-9], while physical activity and physical fitness are assumed to have positive effects on lung function [10-12]. Regarding dietary parameters both the intake of retinol (vitamin A) and the intake of polyunsaturated fatty acids (PUFA) are assumed to have a positive effect on lung function [2, 13-16]. Effects of alcohol consumption on lung function parameters are quite ambiguous $[13,14]$. 
The Amsterdam Growth and Health Study (AGHS) is an observational longitudinal study, in which six repeated measurements were carried out over a period of $15 \mathrm{yrs}$ in males and females aged between 13-27 yrs [17]. From this study, longitudinal data are available of lung function parameters (i.e. forced vital capacity (FVC), forced expiratory volume in one second (FEV1) and peak expiratory flow (PEF)) as well as the lifestyle parameters earlier mentioned and indicators of biological growth and maturation.

The purpose of the present study therefore was to investigate the stability/tracking of lung function parameters in a healthy population of males and females between 13-27 yrs of age and to investigate the relationship between the development of lung function and the development of lifestyle parameters, correcting for biological growth indicators and biological maturation.

\section{Methods}

\section{Subjects}

The AGHS (approved by the medical ethical committee of the Vrije Universiteit, Amsterdam, The Netherlands) is an observational longitudinal study which started in 1977 with healthy subjects from the first and second forms of a secondary school in Amsterdam. Compared to the general Dutch population, the socioeconomic background of the subjects (initially based on profession, education, and income of the parents) was above average. The goals of the AGHS were to describe the natural development of growth, health and lifestyle of a group of healthy adolescent males and females, and to investigate longitudinal relationships between health and lifestyle parameters [17]. At the start of the study 307 subjects (148 males and 159 females) with a mean age of 13 yrs were measured. During the first four years of the study, yearly measurements were carried out. In total, 233 subjects (102 males and 131 females) completed these four annual measurements. Later, two follow-up measurements were carried out. In 1985, at the age of 21 yrs 200 subjects (93 males and 107 females) were measured for the fifth time and in 1991 at the age of 27 yrs a sixth measurement was carried out on 181 subjects ( 83 males and 98 females). For the variables of interest in this study no drop-out effects were observed [17]. Over the entire longitudinal period of $15 \mathrm{yrs}$, complete data were available from 181 subjects. Because 14 subjects suffered from asthma, they were excluded from the study; thus the total number of subjects in the present study was 167 (78 males and 89 females).

\section{Lung function parameters}

Lung function parameters were measured with an electronic spirometer. During the first four years of measurement a Monaghan 403 (Medicare B.V., Uden, the Netherlands) was used. For the last two measurements a Vica test was used (Mijnhardt B.V., Odijk, the Netherlands). The procedure of lung function measurement consisted of a maximal inspiration followed by a maximal and forceful expiration. The subjects were measured in a standing position, wore a noseclip and breathed in a disposable mouthpiece that was connected to the spirometer. The subjects made at least three successful efforts. The highest score was selected for analysis. The following lung function parameters were assessed: FVC, FEV1 and PEF.

\section{Lifestyle parameters}

The amount of daily physical activity was measured with an interviewer administered activity questionnaire developed for the AGHS [18]. It covered a period three months prior to the interview. This questionnaire measured the total time spent on all habitual physical activities in relation to school, work, sports and on other leisure time activities. Measured times were multiplied by the intensity of the different activities to calculate a total weighted activity score (expressed as the number of metabolic equivalents $(\mathrm{METs}) \cdot$ week $^{-1}$ ).

Physical fitness can be divided into neuromotor fitness and cardiopulmonary fitness. Neuromotor fitness was measured with the motor performance fitness test (MOPER) [19]. This test consisted of seven items that measured different aspects of neuromotor fitness. For each subject the scores of the fitness items were ranked; subjects with the best scores were given the highest ranking numbers. The rank numbers on each of the seven fitness tests were added for each subject to obtain an overall ranking score. This procedure was carried out for males and females separately. Maximal oxygen consumption $\left(V^{\prime} \mathrm{O}_{2}, \max \right)$ was used as a measure of cardiopulmonary fitness and was assessed by a maximal running test on a treadmill [20]. $V^{\prime} \mathrm{O}_{2}$, max was expressed independent of body weight $\left(\mathrm{mL} \cdot \mathrm{min}^{-1} \cdot \mathrm{kg}^{-2 / 3}\right)$.

Dietary intake was measured with a cross-check dietary history interview which was specially developed for the AGHS [21]. The interview listed series of items covering the entire range of foods and drinks. Only food items eaten at least twice monthly were recorded. Food items were converted into macro- and micronutrients, using the computerized Dutch Food Composition Table [22]. From the dietary history interview the following nutrients were selected: retinol intake $\left(\mathrm{mg} \cdot \mathrm{day}^{-1}\right)$, PUFA intake $\left(\mathrm{g} \cdot \mathrm{day}^{-1}\right)$ and the intake of alcohol $\left(\mathrm{g} \cdot \mathrm{day}^{-1}\right)$.

Smoking habits of the subjects were requested by a questionnaire. From the questionnaire the total daily amount of tobacco used was calculated $\left(\mathrm{g} \cdot\right.$ day $\left.^{-1}\right)$.

\section{Other parameters}

The development of lung function parameters is highly related to the development of biological growth parameters [1]. Therefore, body height, body weight and biacromial diameter were measured at each of the longitudinal measurements. The natural development of lung function parameters is also related to biological maturation [3]. As a measure of biological maturation, biological age was estimated according to the Tanner-Whitehouse II method using radiographs (Utilis 15/18; Enraf-Nonius, the Netherlands) of the left hand [23]. After full maturation was reached, calendar age was used as an indicator for biological age. 


\section{Statistical analysis}

To analyse the stability of lung function parameters the value of the initial measurement at $t \mathrm{l}$ was regressed on the entire longitudinal development of the same lung function parameter from $t 2$ up to $t 6[5,24]$. The advantages of using this method in calculating stability coefficients are that all available longitudinal data are used to estimate the stability coefficients, and that the method is suitable for designs with unequally spaced time intervals. The resulting stability coefficient can be interpreted as a longitudinal correlation coefficient and ranges between $0-1$. The magnitude of the stability coefficients however, does not give a direct answer to the question of whether it is worthwhile to screen subjects at an early age regarding lung function parameters. Because of this the percentage of subjects from a "risk group" at the initial measurement who maintained their position "at risk" later in life was calculated. To assess this "tracking for subjects at risk", at each measurement the subjects were divided into sex-specific quartiles. With a longitudinal logistic regression analysis, odds ratios (ORs) were calculated for subjects in the highest "risk" quartile compared with subjects in the other three "nonrisk" quartiles in order to maintain the position in the highest "risk" quartile along the measurement period. In designs with only two repeated measurements, the analysis to assess "tracking for subjects at risk" is similar to the calculation of the percentage of subjects from the highest quartile at the first measurement who maintained their position in the highest quartile at the second measurement; this percentage can be transformed easily into an OR. For longitudinal designs with more than two repeated measurements the statistical technique is slightly more complicated, but the principle is the same. The statistical models used to assess stability coefficients and "tracking for subjects at risk" are extensively described in other publications $[5,24,25]$. The parameters of both statistical models were estimated with generalized estimating equations (GEE), which is suitable for the analysis of continuous, as well as dichotomous outcome variables [26].

To analyse the longitudinal relationship between lung function and lifestyle parameters a longitudinal linear regression technique was used, which has also been extensively described elsewhere [27, 28]. As in the stability/ tracking analysis, the longitudinal regression coefficients were estimated with GEE. Besides the fact that the used method has the same advantages as the method used to estimate stability/tracking coefficients, it also allows a correction for both time-dependent (i.e. body height, body weight, biacromial diameter and biological age) and timeindependent covariates (i.e. sex). Two different longitudinal analyses were carried out: an analysis in which the actual/absolute values of the lung function parameters, the lifestyle parameters as well as the covariates were modelled, and an analysis in which the changes between two subsequent measurements in lung function parameters, lifestyle parameters as well as the covariates were modelled. The changes between subsequent measurements were calculated as: $\Delta Y_{i}=\left(Y_{i t}-Y_{i t}+1\right) / Y_{i t} \times 100 \%$. The first analysis is a combined analysis of between-subjects (i.e. cross-sectional) relationships and within-subjects (i.e. longitudinal) relationships, while the second analysis is a better estimate of just the longitudinal relationships [29]. Each of the predictor variables with a univariate value of $p<0.25$ was added to a multiple longitudinal regression model, in which the predictor variables were analysed together, correcting for each other and for the earlier mentioned timedependent and time-independent covariates.

The lifestyle parameters: daily physical activity, physical fitness, the intake of retinol and the intake of PUFA and the time-dependent covariates (i.e. body height, body weight, biacromial diameter and biological age) were treated as continuous. Smoking and alcohol consumption were dichotomized and for both difference values were not calculated, but the values at the last time point of the time interval between two subsequent measurements were used. Before the GEE-analyses were carried out, the values of the lung function parameters and all continuous predictor variables were transformed into $z$-scores in order to account for scale differences. The use of standardized variables in the longitudinal analyses makes the coefficients vary between -1 and +1 and makes the coefficient interpretable as a longitudinal (partial) correlation coefficient. Furthermore, it makes the coefficients belonging to different predictor variables directly comparable; so the strength of the longitudinal relationship is reflected in the magnitude of the regression coefficient. For the lung function parameters, the transformation into $z$-scores is also necessary to account for possible systematic differences between the two methods used to assess the lung function parameters.

Interactions between the predictor variables and sex were added to all statistical models. Interactions between the predictor variables and time were added only to the models regarding the longitudinal relationships. All longitudinal GEE-analyses were carried out with the statistical package for interactive data analysis (SPIDA, Statistical Computing Laboratory, Eastwood, NSW, Australia) [30].

\section{Results}

Table 1 shows descriptive information regarding the lung function parameters and the relative changes in lung function. The same information is given for the lifestyle predictor variables. In table 2 the stability coefficients for the different lung function parameters are given. The magnitude of the coefficients ranged from 0.41 for PEF to 0.66 for FVC (for males) and 0.65 for FEV1 (for males). Because for both $\mathrm{FVC}$ and $\mathrm{FEV} 1$ a significant interaction was found with sex $(\mathrm{p}=0.03$ for $\mathrm{FEV} 1$, and $\mathrm{p}=0.01$ for $\mathrm{FVC})$, different coefficients were calculated for males and females; for both lung function parameters males showed higher values than females. Table 2 also shows ORs related to "tracking for subjects at risk". For FVC an OR of 12.7 was observed, while for FEV1 $(\mathrm{OR}=7.6)$ and PEF $(\mathrm{OR}=5.4)$ this "tracking for subjects at risk" was lower. Because no interactions with sex were observed, these ORs hold for both males and females.

In table 3, the results of the longitudinal analyses regarding the modelling of actual/absolute values are presented. For FVC and FEV1 comparable results were found in both univariate and multiple analysis. Alcohol consumption, neuromotor fitness (only for males) and the intake of PUFA were all positively related to both FVC and FEV1. For neuromotor fitness a significant interaction was found with sex for both FVC and FEV1 $(p<0.01)$; so separate coefficients were calculated for males and females. Regarding PEF, physical activity was found to be 
Table 1. - Mean and (standard deviation) of the absolute values and the relative changes in lung function parameters* and lifestyle predictor variablest for males and females at different ages

\begin{tabular}{|c|c|c|c|c|c|c|c|c|c|c|c|c|c|}
\hline & \multirow{3}{*}{$\frac{\text { Sex }}{\mathrm{M}}$} & \multicolumn{12}{|c|}{ Calendar age yrs } \\
\hline & & \multicolumn{2}{|c|}{13} & \multicolumn{2}{|c|}{16} & \multicolumn{2}{|c|}{$13-16$} & \multicolumn{2}{|c|}{21} & \multicolumn{2}{|c|}{27} & \multicolumn{2}{|c|}{$21-27 \ddagger$} \\
\hline FVC & & 3.06 & $(0.49)$ & 4.13 & $(0.62)$ & -11.3 & (9.6) & 5.53 & $(0.75)$ & 5.70 & $(0.69)$ & -3.3 & $(6.8)$ \\
\hline $\mathrm{L}$ & $\mathrm{F}$ & 2.99 & $(0.58)$ & 3.24 & $(0.50)$ & -3.1 & (7.3) & 4.02 & $(0.58)$ & 4.18 & $(0.50)$ & -4.7 & $(7.0)$ \\
\hline FEV1 & $\mathrm{M}$ & 2.74 & $(0.43)$ & 3.56 & $(0.55)$ & -9.7 & (8.3) & 4.88 & $(0.65)$ & 4.82 & $(0.59)$ & 0.9 & (5.7) \\
\hline $\mathrm{L}$ & $\mathrm{F}$ & 2.77 & $(0.53)$ & 2.88 & $(0.39)$ & -2.1 & (7.4) & 3.57 & $(0.47)$ & 3.56 & $(0.44)$ & 0.1 & $(6.8)$ \\
\hline Peak expiratory flow & $\mathrm{M}$ & 3.03 & $(0.56)$ & 4.16 & $(0.68)$ & -12.6 & (13.7) & 6.40 & $(1.16)$ & 6.60 & (1.18) & -5.0 & (16.4) \\
\hline $\mathrm{L} \cdot \mathrm{s}^{-1}$ & $\mathrm{~F}$ & 3.02 & $(0.57)$ & 3.58 & $(0.65)$ & -11.7 & (16.4) & 4.32 & $(0.85)$ & 4.41 & $(0.88)$ & -4.1 & $(19.3)$ \\
\hline Daily physical activity & $\mathrm{M}$ & 4.99 & $(2.0)$ & 3.70 & $(1.7)$ & 4.1 & $(37.8)$ & 3.45 & (2.2) & 2.91 & $(2.3)$ & 37.9 & (196.8) \\
\hline $1,000 \mathrm{M}$ & $\mathrm{F}$ & 3.81 & (1.7) & 3.35 & (1.7) & 0.6 & (32.1) & 2.35 & (2.1) & 3.18 & (1.9) & -56.3 & $(254.2)$ \\
\hline nary fitness & $\mathrm{M}$ & 210.0 & $(18.3)$ & 232.8 & (21.8) & -3.6 & $(8.4)$ & 222.9 & $(23.6)$ & 212.5 & $(22.0)$ & 4.0 & $(10.3)$ \\
\hline $\mathrm{mL} \cdot \mathrm{min}^{-1} \cdot \mathrm{kg}^{-2 / 3}$ & $\mathrm{~F}$ & 185.0 & $(17.5)$ & 179.2 & (14.5) & 1.3 & (7.3) & 162.6 & (15.9) & 160.8 & (19.5) & 0.1 & $(8.7)$ \\
\hline Retinol intake & M & 0.96 & $(0.29)$ & 1.20 & $(0.35)$ & -11.5 & $(30.8)$ & 1.20 & $(0.35)$ & 1.30 & $(0.47)$ & -16.8 & $(46.0)$ \\
\hline & $\mathrm{F}$ & 0.80 & $(0.24)$ & 0.84 & $(0.32)$ & -6.6 & $(36.8)$ & 0.88 & $(0.37)$ & 1.03 & $(0.32)$ & -28.6 & (47.5) \\
\hline PUFA intake & $\mathrm{M}$ & 18.9 & $(7.8)$ & 22.7 & $(10.1)$ & -13.5 & (44.7) & 24.6 & (8.9) & 22.8 & $(10.7)$ & 2.2 & (47.1) \\
\hline $\mathrm{g} \cdot \mathrm{day}^{-1}$ & $\mathrm{~F}$ & 15.8 & $(8.3)$ & 15.2 & $(7.1)$ & 6.7 & $(43.5)$ & 15.3 & (5.9) & 16.2 & $(6.8)$ & -19.8 & (70.3) \\
\hline Smoking behaviour\# & $\mathrm{M}$ & 1.2 & & 14.5 & & & & 32.5 & & 33.7 & & & \\
\hline$\%$ smokers & $\mathrm{F}$ & 4.1 & & 26.0 & & & & 35.1 & & 23.7 & & & \\
\hline Alcohol consumption" & $\mathrm{M}$ & 8.5 & & 48.1 & & & & 73.1 & & 86.7 & & & \\
\hline$\%$ drinkers & $\mathrm{F}$ & 10.3 & & 59.2 & & & & 75.5 & & 63.3 & & & \\
\hline
\end{tabular}

*: from 13-16 yrs of age, lung function parameters were measured with a Monaghan 403, at the ages of 21 and 27 yrs, lung function parameters were measured with a Vica Test; ${ }^{\dagger}$ : descriptive information on neuromotor fitness is not given, because the total fitness score is based on rank numbers and therefore not informative; $:$ relative changes (between the ages mentioned) were calculated as: $\left(\left[Y_{\mathrm{t}}-Y_{\mathrm{t}+1}\right] / Y_{\mathrm{t}} \times 100\right)$ and expressed in per cent, negative values indicate a relative increase over time; \#: for both dichotomized variables only the per cent of smokers/drinkers is given, no relative changes were calculated. FVC: forced vital capacity; FEV1: forced expiratory volume in one second; METs: metabolic equivalents; PUFA: polyunsaturated fatty acids.

inversely related, while neuromotor fitness showed a positive relationship. The positive relationship between the intake of PUFA and PEF which was found in univariate analysis, did not reach significance $(\mathrm{p}=0.07)$ in a multiple analysis. In table 4 the results of the longitudinal analyses regarding the modelling of changes are presented. The changes in FVC were positively related to smoking behaviour, and positively to changes in daily physical activity. Changes in FEV1 were only positively related to smoking behaviour. For the changes in PEF no significant relationships were observed.

\section{Discussion}

\section{Stability/tracking of lung function parameters}

Until now, stability/tracking analysis has rarely been applied to lung function. For this reason it is difficult to

Table 2. - Stability coefficients* and odds ratios indicating "tracking for subjects at risk" for lung function parameters calculated over a period of 15 yrs covering adolescence and young adulthood

\begin{tabular}{|c|c|c|c|}
\hline & Sex & $\begin{array}{l}\text { Stability } \\
\text { coefficient }\end{array}$ & $\begin{array}{l}\text { Tracking for } \\
\text { subjects at risk }\end{array}$ \\
\hline FVC & M & $0.66(0.54-0.77)$ & $12.7(6.5-24.7)$ \\
\hline FEV 1 & $\begin{array}{l}\mathrm{F} \\
\mathrm{M}\end{array}$ & $\begin{array}{ll}0.51 & (0.43-0.60) \\
0.65 & (0.50-0.80)\end{array}$ & $7.6(4.1-14.3)$ \\
\hline Peak expiratory flow & $\mathrm{F}$ & $\begin{array}{ll}0.53 & (0.46-0.60) \\
0.41 & (0.31-0.51)\end{array}$ & $5.4 \quad(3.2-9.0)$ \\
\hline
\end{tabular}

*: for forced vital capacity (FVC) and forced expiratory volume in one second (FEV1) a significant interaction was found with sex, different stability coefficients were calculated for males and females; ${ }^{\dagger}$ : odds ratios were calculated for sex-specific "high risk" quartiles. M: male; F: female. interpret the values of the calculated stability coefficients in comparison with the results from other studies. In the few studies where the stability for lung function parameters was assessed, different methods were used to calculate stability coefficients. However, in general, reasonably good stability was observed for FVC, and FEV1, as well as for PEF for both males and females [31, 32].

To put the results of our stability analysis into a broader perspective, the coefficients of the present study can be compared with other stability coefficients, calculated over the same time period, with the same method [5]. This comparison showed that the stability coefficients for FVC and FEV 1 for males are of the same order as values for body weight (stability coefficient $\beta=0.65$ ), body fatness $(\beta=0.63)$ and serum cholesterol $(\beta=0.71)$, while the coefficient for PEF is of the same magnitude as the coefficients found for systolic and diastolic blood pressure $(\beta=0.43$ and $\beta=0.34)$ and lifestyle parameters such as dietary intake (fat intake $\beta=0.42$ and carbohydrate intake $\beta=0.32$ ) and physical activity $(\beta=0.34)$. Based on this, stability for FVC and FEV1 for males can be considered as good, and for females as moderate. The stability for PEF can be considered as moderate for both males and females.

As mentioned previously, the magnitude of the stability coefficients does not give a direct answer to the question whether or not subjects should be screened at an early age regarding lung function parameters. Therefore, a second analysis was carried out in which ORs were calculated for subjects in the sex-specific "high risk" quartile in order to maintain their position along the whole longitudinal period of 15 yrs. Like the stability coefficients these ORs can also be compared with ORs calculated over the same time period, and with the same method [5]. The OR for FVC was of the same magnitude as the one for serum cholesterol $(\mathrm{OR}=10.4)$ and slightly lower than the one observed for body fatness $(\mathrm{OR}=17.7)$. All ORs for the lung 
Table 3. - Standardized regression coefficients ${ }^{+}$(95\% confidence intervals) regarding the longitudinal relationship between lung function parameters and lifestyle parameters, when modelling the actual/absolute values at each time point

\begin{tabular}{|c|c|c|c|c|c|c|c|}
\hline & \multirow[b]{2}{*}{ Sex } & \multicolumn{2}{|c|}{ FVC } & \multicolumn{2}{|c|}{ FEV1 } & \multicolumn{2}{|c|}{ PEF } \\
\hline & & Univariate & Multiple $^{\dagger}$ & Univariate & Multiple $^{\dagger}$ & Univariate & Multiple $^{\dagger}$ \\
\hline $\begin{array}{l}\text { Smoking } \\
\text { behaviour }\end{array}$ & & $\begin{array}{c}-0.04 \\
(-0.12-0.05)\end{array}$ & & $\begin{array}{c}-0.03 \\
(-0.11-0.04)\end{array}$ & & $\begin{array}{c}-0.07 \\
(-0.19-0.06)\end{array}$ & \\
\hline $\begin{array}{l}\text { Alcohol } \\
\text { consumption }\end{array}$ & & $\begin{array}{c}0.05^{*} \\
(0.00-0.10)\end{array}$ & $\begin{array}{c}0.05^{*} \\
(0.01-0.11)\end{array}$ & $\begin{array}{c}0.05^{*} \\
(0.01-0.10)\end{array}$ & $\begin{array}{c}0.06^{\#} \\
(0.01-0.11)\end{array}$ & $\begin{array}{c}0.01 \\
(-0.07-0.10)\end{array}$ & \\
\hline $\begin{array}{l}\text { Physical } \\
\text { activity }\end{array}$ & & $\begin{array}{c}0.02^{\$} \\
(-0.01-0.05)\end{array}$ & $\begin{array}{c}0.01 \\
(-0.01-0.04)\end{array}$ & $\begin{array}{c}0.00 \\
(-0.02-0.03)\end{array}$ & & $\begin{array}{c}-0.06 * \\
(-0.12--0.01)\end{array}$ & $\begin{array}{c}-0.07 * \\
(-0.13--0.01)\end{array}$ \\
\hline $\begin{array}{l}\text { Neuromotor } \\
\text { fitness }\end{array}$ & M & $\begin{array}{c}0.18^{* *} \\
(0.11-0.26)\end{array}$ & $\begin{array}{c}0.20 * * \\
(0.12-0.28)\end{array}$ & $\begin{array}{c}0.20^{* *} \\
(0.14-0.27)\end{array}$ & $\begin{array}{c}0.20 * * \\
(0.13-0.27)\end{array}$ & & \\
\hline & $\mathrm{F}$ & $\begin{array}{c}0.04 \\
(-0.01-0.06)\end{array}$ & $\begin{array}{c}0.02 \\
(-0.03-0.07)\end{array}$ & $\begin{array}{c}0.02 \\
(-0.03-0.07)\end{array}$ & $\begin{array}{c}0.00 \\
(-0.06-0.06)\end{array}$ & $\begin{array}{c}0.17 * * \\
(0.11-0.24)\end{array}$ & $\begin{array}{c}0.18^{* *} \\
(0.11-0.25)\end{array}$ \\
\hline $\begin{array}{l}\text { Cardiopulmonary } \\
\text { fitness }\end{array}$ & & $\begin{array}{c}0.01 \\
(-0.4-0.06)\end{array}$ & & $\begin{array}{c}0.01 \\
(-0.02-0.03)\end{array}$ & & $\begin{array}{c}0.04 \\
(-0.03-0.11)\end{array}$ & \\
\hline $\begin{array}{l}\text { Retinol } \\
\text { intake }\end{array}$ & & $\begin{array}{c}0.00 \\
(-0.03-0.03)\end{array}$ & & $\begin{array}{c}0.00 \\
(-0.02-0.03)\end{array}$ & & $\begin{array}{c}-0.01 \\
(-0.05-0.03)\end{array}$ & \\
\hline $\begin{array}{l}\text { PUFA } \\
\text { intake }\end{array}$ & & $\begin{array}{c}0.03^{*} \\
(0.01-0.06)\end{array}$ & $\begin{array}{c}0.03^{*} \\
(0.01-0.06)\end{array}$ & $\begin{array}{c}0.03^{*} \\
(0.01-0.06)\end{array}$ & $\begin{array}{c}0.03 * \\
(0.00-0.06)\end{array}$ & $\begin{array}{c}0.05^{*} \\
(0.01-0.11)\end{array}$ & $\begin{array}{c}0.05 \\
(-0.01-0.10)\end{array}$ \\
\hline
\end{tabular}

†: regression coefficients are interpretable as longitudinal (partial) correlation coefficients; $\uparrow$ : both univariate and multiple analyses corrected for body height, body weight, biacromial diameter, biological age and sex, multiple analysis also corrected for other lifestyle parameters; : for neuromotor fitness a significant interaction with sex was found, different coefficients were calculated for males and females; FVC: forced vital capacity; FEV1: forced expiratory volume in one second; PEF: peak expiratory flow; M: male; F: female; PUFA: polyunsaturated fatty acids. **: $\mathrm{p}<0.01 ; *$ : $\mathrm{p}<0.05 ;$ : $\mathrm{p}<0.025$ (only for univariate analysis).

function parameters were slightly higher than the ones observed for systolic $(\mathrm{OR}=4.8)$ and diastolic blood pressure $(\mathrm{OR}=4.0)$ and for lifestyle parameters such as physical activity $(\mathrm{OR}=3.6)$. The advantage of calculating "tracking for subjects at risk" is that the magnitude of the ORs give an indication of the predictive value of a potential screening at an early age. Suppose tracking is calculated for subjects in a particular "risk" quartile in a longitudinal study with two measurements in time and $50 \%$ of the initial "high risk" quartile maintained their position at the follow-up measurement. In this situation the initial measurement (i.e. "the potential screening test") had a predictive value of 50\% and an OR of 5.0. This means that an OR of 5.0 calculated for "risk" quartiles translates to a predictive value of the initial measurement of $50 \%$; in a similar way an OR of 10.0 calculated for "risk" quartiles translates to a predictive value of $60 \%$. Because in the present study all available longitudinal data were used in the analysis, ORs cannot be directly transformed into predictive values of a potential screening. However, they will give an indication of the predictive value of a potential screening. The interpretation of the stability and tracking coefficients provide (statistical) arguments in favour (e.g. for FVC) or against (e.g. for PEF) the screenability of young subjects regarding lung function parameters. However, before deciding whether or not it is worthwhile to screen subjects at an early age, many other considerations should be made. Firstly, the presented stability/tracking analysis focuses on

Table 4. - Standardized regression coefficients ${ }^{+}$(95\% confidence intervals) regarding the longitudinal relationship between lung function parameters and lifestyle parameters, when modelling the changes between subsequent measurements

\begin{tabular}{|c|c|c|c|c|c|c|}
\hline & \multicolumn{2}{|c|}{ FVC } & \multicolumn{2}{|c|}{ FEV1 } & \multicolumn{2}{|c|}{ PEF } \\
\hline & Univariate & Multiple $^{\dagger}$ & Univariate & Multiple $^{\dagger}$ & Univariate & Multiple $^{\dagger}$ \\
\hline Smoking & $0.22 * *$ & $0.23 * *$ & $0.17 * *$ & $0.17 * *$ & 0.03 & \\
\hline behaviour & $(0.10-0.33)$ & $(0.12-0.34)$ & $(0.04-0.29)$ & $(0.05-0.30)$ & $(-0.13-0.20)$ & \\
\hline $\begin{array}{l}\text { Alcohol } \\
\quad \text { consumption }\end{array}$ & $\begin{array}{c}-0.05 \\
(-0.16-0.06)\end{array}$ & & $\begin{array}{c}-0.05 \\
(-0.15-0.05)\end{array}$ & & $\begin{array}{c}0.00 \\
(-0.13-0.13)\end{array}$ & \\
\hline $\begin{array}{l}\text { Physical } \\
\text { activity }\end{array}$ & $\begin{array}{c}0.11^{*} \\
(0.02-0.20)\end{array}$ & $\begin{array}{c}0.11 * \\
(0.02-0.20)\end{array}$ & $\begin{array}{c}0.03 \\
(-0.09-0.11)\end{array}$ & & $\begin{array}{c}-0.02 \\
(-0.10-0.05)\end{array}$ & \\
\hline $\begin{array}{l}\text { Neuromotor } \\
\text { fitness }\end{array}$ & $\begin{array}{c}-0.03 \\
(-0.09-0.04)\end{array}$ & & $\begin{array}{c}-0.03 \\
(-0.09-0.04)\end{array}$ & & $\begin{array}{c}-0.06^{\$} \\
(-0.13-0.01)\end{array}$ & $\begin{array}{c}-0.07 \\
(-0.13-0.00)\end{array}$ \\
\hline $\begin{array}{l}\text { Cardiopulmonary } \\
\text { fitness }\end{array}$ & $\begin{array}{c}-0.01 \\
(-0.08-0.06)\end{array}$ & & $\begin{array}{c}0.02 \\
(-0.05-0.08)\end{array}$ & & $\begin{array}{c}0.05^{\$} \\
(-0.02-0.11)\end{array}$ & $\begin{array}{c}0.04 \\
(-0.02-0.11)\end{array}$ \\
\hline $\begin{array}{l}\text { Retinol } \\
\text { intake }\end{array}$ & $\begin{array}{c}0.04 \\
(-0.03-0.10)\end{array}$ & & $\begin{array}{c}0.03 \\
(-0.03-0.10)\end{array}$ & & $\begin{array}{c}0.01 \\
(-0.05-0.06)\end{array}$ & \\
\hline $\begin{array}{l}\text { PUFA } \\
\text { intake }\end{array}$ & $\begin{array}{c}0.06^{\$} \\
(-0.01-0.12)\end{array}$ & $\begin{array}{c}0.06 \\
(0.00-0.13)\end{array}$ & $\begin{array}{c}0.04^{\$} \\
(-0.02-0.10)\end{array}$ & $\begin{array}{c}0.05 \\
(-0.02-0.11)\end{array}$ & $\begin{array}{c}0.04 \\
(-0.03-0.11)\end{array}$ & \\
\hline
\end{tabular}

+ : regression coefficients are interpretable as longitudinal (partial) correlation coefficients; ${ }^{\dagger}$ : both univariate and multiple analyses corrected for body height, body weight, biacromial diameter, biological age and sex, multiple analysis also corrected for other lifestyle parameters; FVC: forced vital capacity; FEV1: forced expiratory volume in one second; PEF: peak expiratory flow; PUFA: polyunsaturated fatty acids. $* *: \mathrm{p}<0.01 ; *: \mathrm{p}<0.05 ; \$: \mathrm{p}<0.25$ (only for univariate analysis). 
the longitudinal development of lung function parameters, but not on the actual risk of developing chronic lung disease. Lung function parameters measured at an early age are a (less than perfect) predictor of lung function parameters in middle age, which are a (less than perfect) predictor of the development of chronic lung disease. Thus, "impaired" lung function in childhood or adolescence is a risk factor for chronic lung disease. Secondly, there is no evidence that risk reduction for the development of chronic lung disease is more effective if preventive intervention starts in childhood or adolescence, and thirdly there is no evidence that screening and intervention in childhood or adolescence can be accomplished with little risk to the subject. Furthermore, the cost-effectiveness of a screening procedure should be taken into account; although the cost of screening should not be great, especially not if conducted as part of routine paediatric care. Finally, an important issue is the availability of preventive intervention methods. As mentioned before, changing lifestyle is the prime candidate for possible intervention. Therefore, in the second part of the present study the longitudinal relationship between lung function and lifestyle parameters was analysed.

\section{Lifestyle in relation to lung function}

For longitudinal relationships, it is also difficult to compare the present results with the literature. Firstly, most other studies were cross-sectionally designed, and when they were longitudinal, more simplified statistical methods were used to analyse longitudinal relationships. Secondly, in the present study lung function was related to lifestyle in a young and healthy population, while in many other studies lifestyle parameters were related to the occurrence of clinical symptoms. The fact that the relationships were analysed in a young and healthy population is, however, necessary to interpret the results in relation to the screenability of young subjects for lung function.

Regarding the longitudinal relationship between smoking behaviour and lung function, the results of the present study indicate that smoking does not have much influence on the absolute values of FVC and FEV1, but that smoking is related to a negative development of these lung function parameters (i.e. related to a decrease in lung function). A relationship between smoking and lung function was found in many other studies. TAGER et al. [7] found that even small amounts of cigarette use by adolescents led to a decreased growth of lung function over time. SHERILL et al. [33] examined the effects of smoking onset and cessation on the pulmonary function of subjects of $18 \mathrm{yrs}$ and older. Quitting smoking was shown to have a beneficial effect on lung function, while starting smoking was shown to be related to a more rapid decline of lung function. Several other studies have also demonstrated a deleterious effect of smoking on the development of lung function $[9,34]$.

Regarding alcohol consumption, a positive relationship was observed in the present study with FVC and FEV1 in the modelling of actual/absolute values. SPARROw et al. [14] found no relationships between alcohol consumption and FVC and FEV1 in both a cross-sectional and a longitudinal study, while LEBowItz [13] found an inverse relationship between lung function and alcohol consumption. How- ever, this relationship was only observed in heavy smokers.

When modelling actual/absolute values, daily physical activity was surprisingly found to be inversely related to PEF. When changes between subsequent measurements were modelled, an (expected) positive relationship was found with FVC. In the literature the relationship between habitual physical activity and lung function in younger age groups is not well documented. MiLer et al. [10] found in a cross-sectional study little evidence that physical activity was positively related to FVC. Also in older subjects no consistent results were reported. HAGBERG et al. [11], for instance, compared lung function of older athletes with their sedentary counterparts and concluded that the deterioration of lung function in athletes was less than "normal". McClaren et al. [12] on the other hand did not find any advantages in older athletes.

In the modelling of actual/absolute values neuromotor fitness was positively related to all lung function parameters. When changes were modelled, however, no significant relationships were observed. Thus, neuromotor fitness does not seem to have a positive influence on the development of lung function. RoOSENTHAL et al. [3] stated that physical fitness (i.e. muscle strength) is thought to be related to lung function, because it will contribute to the forced manoeuvres involved in the measurement of lung function parameters.

Cardiopulmonary fitness was not found to be related to any of the lung function parameters in both longitudinal analyses. This is not in agreement with MILLER et al. [10] who found a relationship between improved performance on a cycle ergometer test and increased FVC.

Regarding dietary intake, no relationships were found between the intake of retinol and any of the lung function parameters in both longitudinal analyses. In the literature there is, however, some evidence of an inverse relationship between dietary retinol and airway obstruction, as de-termined from spirometric measurements [9, 35]. For the intake of PUFA, in the modelling of actual/absolute values, positive relationships were found with FVC, FEV1 and PEF. However, for the latter, a significant relationship was found only in univariate analysis, while in the multiple longitudinal analysis, the relationship almost reached significance $(p=0.07)$. In the modelling of changes no significant relationships were observed. Different studies have linked a high fish consumption (which is related to a high intake of PUFA) with a lower occurrence of respiratory symptoms $[2,15]$. It is also suggested that the intake of PUFA may protect the lung against the deleterious effects of smoking $[16,36]$. To investigate this effect, in the present study the interaction between smoking behaviour and the intake of PUFA was added to the final model with changes of subsequent measurements. However, the results of the analyses showed no significant interaction effects with both FVC and FEV1 $(p=0.92$ and $p=0.98$, respectively). Thus, in the present study the protective role of the intake of PUFA on the negative effects of smoking on lung function could not be confirmed.

In general, the results of the longitudinal analyses revealed that intervention strategies relating to the deceleration of the natural decline in lung function should focus on smoking cessation and the improvement of daily physical activity. When the results of these analyses were related to the question of whether or not it is worthwhile 
to screen subjects at an early age, one should consider that the benefits of smoking cessation and improving physical activity are not limited to the subjects who would have been screened as having "impaired" lung function; the possible preventive strategies are a benefit for the whole population. In other words, based on the results of the longitudinal analyses, the necessity of screening subjects at a young age regarding lung function parameters is very doubtful.

\section{General comments}

One of the problems in longitudinal studies can be incomplete follow-up and nonresponse. In the present study, however, the longitudinal analysis was limited to those subjects who were present at the initial measurement at the age of $13 \mathrm{yrs}$ and at the final measurement at the age of $27 \mathrm{yrs}$. Thus, both the results of the stability/tracking analysis and the analysis of longitudinal relationships were not biased by incomplete follow-up. The only problem related to this is the fact that the population under study is relatively small and (perhaps) not a good representation of the general population; this should be taken into ac-count when the results of the present study are interpreted. The percentage of missing observations along the measurement period for the population under study was $\sim 2 \%$, which is rather low.

In conclusion, the present study showed high to moderate stability/tracking for forced vital capacity and forced expiratory volume in one second. For peak expiratory flow, stability/tracking was slightly lower. However, before deciding whether or not it is worthwhile to screen lung function parameters in subjects at an early age, many other factors should be considered. The different longitudinal analyses regarding the relationship between lung function parameters and lifestyle revealed that preventive strategies to improve lung function should target on smoking cessation and improving daily physical activity. The benefits of those preventive strategies are, however, not limited to subjects with "impaired" lung function; thus the need for screening of subjects with "impaired" lung function is very questionable.

\section{References}

1. Quanjer PhH, Stocks J, Polgar G, Wise M, Karlberg J, Borsboom G. Compilation of reference values for lung function measurements in children. Eur Respir J 1989; 2: Suppl. 4, 184s-261s.

2. Schwartz J, Weiss ST. Dietary factors and their relation to respiratory symptoms: the second national health and nutrition examination survey. Am J Epidemiol 1990; 132: 67-76.

3. Roosenthal M, Cramer D, Bain SH, Denison D, Bush A, Warner JO. Lung function in white children aged 4 to 19 years: I. Spirometry. Thorax 1993; 48: 794-802.

4. Twisk JWR, Kemper HCG, Mellenbergh GJ. The mathematical and analytical aspects of tracking. Epidemiol Rev 1994; 16: 165-183.

5. Twisk JWR, Kemper HCG, van Mechelen W, Post GB. Tracking of risk factors for coronary heart disease over a 14 year period: a comparison between lifestyle and biolo- gical risk factors with data from the Amsterdam Growth and Health Study. Am J Epidemiol 1997; 145: 888-898.

6. Wise RA. Changing smoking patterns and mortality from chronic obstructive pulmonary disease. Prev Med 1997; 26: 418-421.

7. Tager IB, Munoz A, Rosner B, Weiss ST, Carey V, Speizer FE. Effect of cigarette smoking on the pulmonary function of children and adolescents. Am Rev Respir Dis 1985; 131: 752-759.

8. Knudson RJ, Dwyn E, Knudson BA, Kaltenborn WT, Bloom JW. Subclinical effects of cigarette smoking: a five year follow-up of physiologic comparisons of healthy middle-aged smokers and nonsmokers. Chest 1989; 95: 512-518.

9. Morabia A, Sorenson A, Kumanyika SK, Abbey H, Cohen $\mathrm{BH}$, Chee E. Retinol, cigarette smoking and airway obstruction. Am Rev Respir Dis 1989; 140: 1312-1316.

10. Miller GJ, Saunders MJ, Gilson RJC, Ashcroft MT. Lung function of healthy boys and girls in Jamaica in relation to ethnic composition, test exercise perforrnance, and habitual physical activity. Thorax 1977; 32: 486-496.

11. Hagberg JM, Yerg II JE, Seals DR. Pulmonary function in young and older athletes and untrained men. $J$ Appl Physiol 1988; 65: 101-105.

12. McClaren SR, Babcock MA, Pegelow DF, Reddan WG, Dempsey JA. Longitudinal effects of aging on lung function at rest and exercise in healthy active fit elderly adults. J Appl Physiol 1995; 78: 1957-1968.

13. Lebowitz MD. Respiratory symptoms and disease related to alcohol consumption. Am Rev Respir Dis 1981; 123: 16-19.

14. Sparrow D, Rosner B, Cohen M, Weiss ST. Alcohol consumption and pulmonary function: a cross-sectional and longitudinal study. Am Rev Respir Dis 1983; 127: 735738.

15. Shahar E, Folsom AR, Melnick SL, et al. Does dietary vitamin A protect against airway obstruction? Am J Respir Crit Care Med 1994; 150: 978-982.

16. Sharp DS, Rodriguez BL, Shahar E, Hwang L-J, Burchfiel CM. Fish consumption may limit the damage of smoking on the lung. Am J Respir Crit Care Med 1994; 150: 983-987.

17. Kemper HCG, ed. The Amsterdam Growth Study: A Longitudinal Analysis of Health, Fitness and Lifestyle. HK Sports Science Monograph Series, Vol 6. Champaign, IL, Human Kinetics, 1995.

18. Verschuur R. Daily physical activity and health. Longitudinal changes during the teenage period. $\mathrm{PhD}$ Thesis, Universiteit van Amsterdam: Haarlem, de Vrieseborch, 1987.

19. Kemper HCG, Verschuur R, Bovend'eerdt J. The MOPER Fitness Test: I. A practical approach to motor performance tests in physical education in the Netherlands. $S$ Afr J Resp Sport Phys Educ Recreat 1979; 2: 81-93.

20. Kemper HCG, Verschuur R. Maximal aerobic power in 13- and 14-year old teenagers in relation to biological age. Int J Sports Med 1981; 2: 97-100.

21. Post GB. Nutrition in adolescence, a longitudinal study in dietary patterns from teenage to adult. PhD Thesis, Agricultural University Wageningen, Haarlem, de Vrieseborch, 1989.

22. Dutch Food and Nutrition Table (in Dutch). Stichting NEVO, Voorlichtingsburo voor de voeding, 1985.

23. Tanner JM, Whitehouse RH, Marshall WA, Healy MJR, Goldstein H. Assessment of Skeletal Maturity and Prediction of Adult Height (TW 2 Method). London, Academic Press, 1975. 
24. Twisk JWR, Kemper HCG, Mellenbergh GJ, van Mechelen W. Factors influencing tracking of cholesterol and high density lipoprotein: The Amsterdam Growth and Health Study. Prev Med 1996; 25: 355-364.

25. Twisk JWR, Kemper HCG, Mellenbergh GJ, van Mechelen W. A new approach to tracking of subjects at risk for hypercholesteremia over a period of 15 years; The Amsterdam Growth and Health Study. Eur J Epidemiol 1997; 13: 293-300.

26. Zeger SL, Liang K-Y. Longitudinal data analysis for discrete and continuous outcomes. Biometrics 1986; 42: 121-130.

27. Twisk JWR, Kemper HCG, Mellenbergh GJ, van Mechelen W. Relation between the longitudinal development of lipoprotein levels and lifestyle parameters during adolescence and young adulthood. Ann Epidemiol 1996; 6: 246-256.

28. Twisk JWR, Kemper HCG, Mellenbergh GJ, van Mechelen W. Relation between the longitudinal development of lipoprotein levels and biological parameters during adolescence and young adulthood in Amsterdam. $J$ Epidemiol Community Health 1996; 50: 505-511.

29. Twisk JWR. Different statistical models to analyse epidemiological observational longitudinal data. Int J Sports Med 1997; 18 (Suppl. 3): S216-S224.
30. Gebski V, Leung O, McNeil D, Lunn D. SPIDA User Manual, version 6. NSW Australia: Macquarie Univ, 1992.

31. Dockery DW, Berkey CS, Ware JH, Speizer FE, Ferris BG. Distribution of forced vital capacity and forced expiratory volume in one second in children 6 to 11 years of age. Am Rev Respir Dis 1983; 128: 405-412.

32. Hibbert ME, Hudson IL, Lanigan A, Landau LI, Phelan PD. Tracking of lung function in healthy children and adolescents. Pediatr Pulmonol 1990; 8: 172-177.

33. Sherill DL, Holberg CJ, Enright PL, Lebowitz MD, Burrows B. Longitudinal analysis of the effects of smoking onset an cessation on pulmonary function. Am J Respir Crit Care Med 1994; 149: 591-597.

34. Tager IB, Segal MR, Speizer FE, Weiss ST. The natural history of forced expiratory volumes: effect of cigarette smoking and respiratory symptoms. Am Rev Respir Dis 1988; 138: 837-849.

35. Morabia A, Menkes MJS, Comstock GW, Tockman MS. Serum retinol and airway obstruction. Am J Epidemiol 1990; 132: 77-82.

36. Shahar E, Folsom AR, Melnick SL, et al. Dietary n-3 polyunsaturated fatty acids and smoking related chro- nic obstructive pulmonary disease: atherosclerosis risk in communities study investigators. N Engl J Med 1994; 331: 228-233. 